\title{
Antioxidant capacity of different cheeses: Affecting factors and prediction by near infrared spectroscopy
}

\author{
I. Revilla, ${ }^{* 1}$ M. I. González-Martín,† A. M. Vivar-Quintana, ${ }^{*}$ M. A. Blanco-López, ${ }^{*}$ I. A. Lobos-Ortega,‡ \\ and J. M. Hernández-Hierro§ \\ ${ }^{*}$ Food Technology Area, University of Salamanca, E. P. S. de Zamora, Avda. Requejo 33, 49022, Zamora, Spain \\ †Department of Analytical Chemistry, Nutrition and Bromatology, Faculty of Chemistry, University of Salamanca, \\ Plaza de la Merced s/n. 37008 Salamanca, Spain \\ $\ddagger$ National Institute of Agriculture and Livestock Research Remehue, Carretera Panamericana Sur Km 8, Osorno, Chile 5290000 \\ §Food Color and Quality Laboratory, Department of Nutrition and Food Science, Universidad de Sevilla, Facultad de Farmacia, \\ 41012 Sevilla, Spain
}

\section{ABSTRACT}

In this study, we analyzed antioxidant capacity of 224 cheese samples prepared using 16 varied mixtures of milk from cows, ewes, and goats, in 2 manufacturing seasons (winter and summer), and over 6 mo of ripening. Antioxidant capacity was evaluated using the spectrophotometric 2,2-azinobis(3-ethylenebenzothiazoline6-sulfonic acid) (ABTS) method. Total antioxidant capacity was significantly correlated with season of manufacturing and time of ripening but not with animal species providing the milk. Moreover, statistically significant correlations between the total antioxidant capacity and retinol $(\mathrm{r}=0.399)$, fat percentage $(\mathrm{r}=$ $0.308)$, protein percentage $(\mathrm{r}=0.366), \mathrm{K}(\mathrm{r}=0.385)$, $\mathrm{Mg}(\mathrm{r}=0.312), \mathrm{Na}(\mathrm{r}=0.432)$, and $\mathrm{P}(0.272)$ were observed. We evaluated the use of near infrared spectroscopy technology, together with the use of a remote reflectance fiber-optic probe, to predict the antioxidant capacity of cheese samples. The model generated allowed us to predict antioxidant capacity in unknown cheeses of different compositions and ripening times.

Key words: cow, ewe, and goat milks, ripening, season, cheese composition

\section{INTRODUCTION}

The oxidative stability of milk and dairy products is of concern to the dairy industry because oxidation processes in milk can result in strong off-flavors and a deterioration of its nutritional quality (Dimick and Kilara, 1983), and also because dairy products can be beneficial for the oxidative defense in consumers through several mechanisms (Bounous, 2000; Steijns and van Hooijdonk, 2000).

Received October 26, 2015.

Accepted February 21, 2016.

${ }^{1}$ Corresponding author: irevilla@usal.es
The antioxidant capacity of milk and dairy products is the result of a complex equilibrium. Milk antioxidants play important roles in preventing lipid peroxidation and maintaining milk quality (Lindmark-Månsson and Åkesson, 2000). In this sense, milk and milk fractions (e.g., skim milk, whey, casein and lactoferrin) have been found to have antioxidant properties (Colbert and Decker, 1991; Cervato et al., 1999; Steijns and van Hooijdonk, 2000). Moreover, carotenoids, tocopherols, ascorbate, ureate, and other low-weight compounds (Clausen et al., 2010; de Renobales et al., 2012), together with enzymes such as glutathione peroxidase, play an important role in preventing milk lipid oxidation (Lindmark-Månsson et al., 2001). In contrast, other compounds such as polyunsaturated lipids and metals render milk more vulnerable to oxidation (Focant et al., 1998).

The composition of the feed partly influences the composition of milk; hence, certain feeding regimens could modify total antioxidant capacity. Pasture-based diets, which are seasonal, are associated with higher levels of xanthophyll, retinol, and $\alpha$-tocopherol in goat, ewe, and cow milks (Rubino et al., 2000; Lucas et al., 2006a, 2008b). Recent studies carried out with sheep milk have demonstrated that Trolox equivalent antioxidant capacity (TEAC) is primarily associated with milk caseins, but it has also been reported that grazing increases TEAC significantly due to the presence of lowmolecular-weight components in whey (de Renobales et al., 2012), such as phenolic compounds, as observed in the milk of grazing goats (De Feo et al., 2006). High contents of phenols in milk have been shown to improve the oxidative stability of dairy products (O'Connell and Fox, 2001). Nevertheless, grazing-based diets are correlated with higher levels of PUFA (Mel'uchova et al., 2008; D'Urso et al., 2008). Total vitamin contents also depend on the synthetic compounds added as supplements to the diet (Meglia et al., 2006), whereas the supplementation of dairy ruminant diets with vegetable 
oils, oilseeds, fish oil, or marine algae increases the proportions of MUFA and PUFA, as reviewed recently by Shingfield et al. (2013).

Work addressing the antioxidant capacity of cheeses is somewhat scarce but there is increasing interest in this field. Although total antioxidant capacity is determined by the cheese-making process itself (Lucas et al., 2006b), it is mainly correlated with fat-soluble vitamins (Lucas et al., 2006b, 2008b). Moreover, TEAC depends on ripening time and is related to the rate of formation of soluble antioxidant peptides as proteolysis progresses (Gupta et al., 2009; Perna et al., 2015).

The primary aim of the present work was to study the factors affecting the antioxidant capacity of cheeses prepared with cow, ewe, and goat milks at different proportions, with ripening times of up to $6 \mathrm{mo}$ and using milk collected in winter or summer to establish the effect of species, ripening, and seasonality, as well as to determine parameters, such as fat composition, protein and peptide contents, mineral composition, and fat-soluble vitamins, with which the antioxidant capacity was correlated. To accomplish this, 224 cheeses were prepared, controlled, and analyzed. A second aim was to assess the application of near infrared spectroscopy (NIRS) to the prediction of the antioxidant capacity in cheeses of variable composition. Application of the NIRS technique to the determination of the antioxidant capacity in cheeses allows conventional analytical methods to be replaced by techniques that are multiparametric, less costly, faster, and do not involve sample destruction.

\section{MATERIALS AND METHODS}

\section{Samples}

To perform the present study, 224 cheeses of known composition; that is, cheeses with known, varying proportions of milk from cows, ewes, and goats, with percentages ranging between 0 and $100 \%$ (Table 1), were prepared following the procedure described by González-Martín et al. (2011b) and controlled. To do this, raw bovine, ovine, and caprine milks were collected directly from farms in winter and then 16 different compositions were collected in winter and again in summer. Cheeses were monitored over 6 mo and individual cheese samples were analyzed at $0,1,2,3,4,5$, and 6 mo. In total, 112 winter cheeses and 112 summer cheeses were analyzed.

\section{TEAC Analysis}

Total antioxidant capacity was determined by the ABTS method, which is based on the reduction of the 2,2-azinobis(3-ethylenebenzothiazoline-6-sulfonic acid) radical cation. Scavenging of the $\mathrm{ABTS}^{\bullet+}$ radical was monitored by the decrease in absorbance at $734 \mathrm{~nm}$ by spectrophotometry (Chen et al., 2003). The ABTS method was modified from that described by Re et al. (1999). The water-soluble vitamin E analog Trolox (6-hydroxy-2,5,7,8-tetramethylchorman-2-carboxylic acid) was used as standard. Samples for analysis were prepared by diluting $2.5 \mathrm{mg}$ of ground cheese in $10 \mathrm{~mL}$ of water. After stirring in a water bath at $40^{\circ} \mathrm{C}$, the mixture was centrifuged at $20^{\circ} \mathrm{C}$ for $30 \mathrm{~min}(3,000 \times \mathrm{g})$ and the supernatant was recovered and brought up to a final volume of $10 \mathrm{~mL}$.

To prepare the ABTS radical cation, an ABTS solution was oxidized in water by treatment with potassium persulfate (molar ratio $=1: 0.35$ ) for 12 to $16 \mathrm{~h}$ in the dark, and then diluted in a 2 -mL cuvette with $0.1 M$ potassium phosphate buffer, $\mathrm{pH} 7.4$, before the assays, giving an absorbance of $0.7 \pm 0.02$ at $734 \mathrm{~nm}$. A suitable amount of sample $(20 \mu \mathrm{L})$ was added to the reagent and the mixture was incubated at $25^{\circ} \mathrm{C}$. Absorbance was recorded every minute for $10 \mathrm{~min}$ using a Shimadzu spectrophotometer (Shimadzu UV-1603, Duisburg, Germany). Appropriate solvent blanks were run in each assay and each sample were analyzed in triplicate. The percentage of inhibition of absorbance at $734 \mathrm{~nm}$ was calculated and plotted as a function of the concentration of Trolox, resulting in the TEAC ( $\mu \mathrm{mol}$ of Trolox/mg of cheese).

\section{Chemical Composition}

Crude protein composition (Kjeldahl method, N $\times 6.38$ ) was analyzed using the AOAC International (1995) method, and total fat content was determined using the method of Geber van Gulik (ISO, 1975). All

Table 1. Composition (\%) of the reference cheeses elaborated (winter and summer milk)

\begin{tabular}{lrc}
\hline Cow milk & Ewe milk & Goat milk \\
\hline 100 & 0 & 0 \\
0 & 100 & 0 \\
75 & 25 & 0 \\
50 & 50 & 0 \\
25 & 75 & 0 \\
0 & 0 & 100 \\
25 & 0 & 75 \\
50 & 0 & 50 \\
75 & 0 & 25 \\
0 & 25 & 75 \\
0 & 50 & 50 \\
0 & 75 & 25 \\
33 & 33 & 33 \\
10 & 45 & 45 \\
45 & 10 & 45 \\
45 & 45 & 10 \\
\hline
\end{tabular}


analyses were carried out in duplicate and the results are expressed in percent by weight. The concentrations of vitamin A (all trans retinol) and vitamin $\mathrm{E}$ in the cheeses were measured as described in Revilla et al. (2014) and expressed in milligrams per $100 \mathrm{~g}$ of cheese. The mineral composition ( $\mathrm{Ca}, \mathrm{P}, \mathrm{K}, \mathrm{Na}$, and $\mathrm{Mg}$ ) measurements were performed by inductively coupled plasma-optical emission spectroscopy (ICP-OES), after mineralization, at the Chemical Analysis Service of the Salamanca University (Salamanca, Spain), as reported by González-Martín et al. (2011a).

\section{Near Infrared Spectroscopy}

A Foss NIRSystem 5000 (Foss A/S, Hillerød, Denmark) with a standard 1.5-m 210/7210 bundle fiberoptic probe (R6539-A) was used. The probe uses a remote reflectance system and a ceramic plate as reference. The window is quartz, with a $5 \times 5 \mathrm{~cm}$ surface area, measuring reflectance in the infrared zone close to 1,100 to $2,000 \mathrm{~nm}$. Spectra were recorded at intervals of $2 \mathrm{~nm}$, performing 32 scans for both the references and samples. To minimize sampling error, all samples were analyzed in triplicate. The software used was Win ISI 1.50, installed on a Hewlett-Packard Pentium III computer (Hewlett-Packard, Palo Alto, CA). The NIR spectra were recorded in reflectance mode, applying the fiber-optic probe directly onto the cheese sample, with no sample preparation or manipulation.

\section{Statistical Analyses}

To study the different factors involved-ripening time, seasonality, and type of milk - we used the SPSS package for Windows 22 (SPSS/IBM Corp., Armonk, NY). To study the influence of ripening time or seasonality, all samples taken in the same month of ripening or in the same season were considered repeated measures. To study the effect of type of milk, a cheese was classified as ewe, goat, or cow milk cheese when it contained $\geq 75 \%$ of milk from each of these species. The mean values of the quantitative variables were compared using ANOVA. The statistical significance of each factor considered was calculated at a $P<0.05$ level using the $F$-test.

The Pearson correlation coefficient test was performed with a 2-tailed test of significance to study the correlation of month of ripening and season with the antioxidant capacity. Pearson correlation coefficients between total fat and protein content, mineral composition, retinol and $\alpha$-tocopherol contents, and antioxidant capacity were also calculated.

Chemometric techniques for the NIR calibration of the antioxidant capacity of the cheeses were performed.
To obtain calibration equations for antioxidant capacity, the data from the NIR spectra and the chemical data of 160 samples (samples from the calibration set) were used. The rest of the samples (64 samples) were assigned to the validation set. Initially, a principal component analysis was used. Once the number of principal components had been determined, the spectral anomalies were analyzed using the Mahalanobis distance $(\mathrm{H}$ statistic), establishing a value of $\mathrm{H}=3$ as the limit value. Accordingly, the samples with an $H$ value $>3.0$ were considered different from the spectral population and removed from the set.

Calibrations were performed by modified partial least squares regression (MPLS). Another criterion to consider is the $\mathrm{T}$ criterion and this is based on chemical parameters (differences between the laboratory value and the NIRS-predicted value). The samples with a $\mathrm{T}$ value $>2.5$ were removed from the set because they were different from the population. In MPLS, the NIR residuals at each wavelength, obtained after each factor has been calculated, are standardized (dividing by the standard deviations of the residuals at each wavelength) before the next factor is calculated. Taking into account both the $\mathrm{H}$ and $\mathrm{T}$ criteria, the calibration process was performed with the spectra of the resulting samples (154) and their chemical data.

When developing MPLS equations, cross-validation is recommended to select the optimal number of factors and to avoid overfitting (Shenk and Westerhaus, 1995). For cross-validation, the calibration sample set was divided into a series of subsets for its calibration. The data set was used to establish 7 series; of these, 6 were taken for the calibration set and the other 1 for the prediction set. The process was repeated as many times as there were sets, such that all samples would pass through the calibration and the prediction sets. With this process, the prediction capacity was checked. Finally, validation errors are combined in a standard error of cross-validation (SECV; Davies and Williams, 1996). To obtain the multivariate regression equations, the detrend treatment (DT) was used as a method for scatter correction (Dhanoa et al. 1995). Moreover, a mathematical treatment was tested in the development of the NIRS calibrations, using a nomenclature of $2,4,4,1$, where the first digit is the number of the derivative; the second is the gap over which the derivative is calculated; the third is the number of data points in a running average, or smoothing; and the fourth is the second smoothing (Shenk and Westerhaus, 1995).

The statistics used to select the best equations were $\mathrm{R}^{2}$ (coefficient of determination) and SECV and the prediction capacity, evaluated as residual predictive deviation (RPD), which is based on the relationship between the standard deviation of the chemical method 
Table 2. Chemical data of the antioxidant capacity in cheese

\begin{tabular}{lccccc}
\hline Item & $\mathrm{N}^{1}$ & Mean & Minimum & Maximum & SD \\
\hline Antioxidant capacity, $\mu$ mol of Trolox $/$ mg of cheese & 224 & 7,005 & 3,064 & 9,543 & 1,324 \\
\hline${ }^{1} \mathrm{~N}=$ number of samples. & & & &
\end{tabular}

(reference SD) and the standard error of prediction (SEP). The RPD should be as high as possible.

\section{RESULTS AND DISCUSSION}

\section{Effects of Animal Species, Season, and Ripening}

The descriptive analysis (maximum, minimum, mean, and SD) of the antioxidant capacity in the cheese samples analyzed with the reference ABTS method are shown in Table 2 . The marked variability in the results reflects the very diverse compositions of the cheese samples due to species, season, and ripening period. Figure 1 shows the influence of these factors (species, season, and ripening) on the antioxidant activity of the cheeses made with ewe, goat, and cow milk throughout the 6 mo of ripening for the winter and summer seasons.

Statistical analysis revealed that seasonality and ripening time had a significant effect on antioxidant capacity $(P<0.05)$. A direct correlation was observed between ripening time and TEAC $(\mathrm{r}=0.296, P<$ 0.01 ). Figure 1 shows that antioxidant capacity increased significantly with the progression of ripening, until a maximum was reached at 3 mo of ripening for winter samples and between 1 and 4 mo for summer samples, and decreasing thereafter, although this decrease was not statistically significant for goat and ewe winter cheeses. For cheeses made with summer milk,

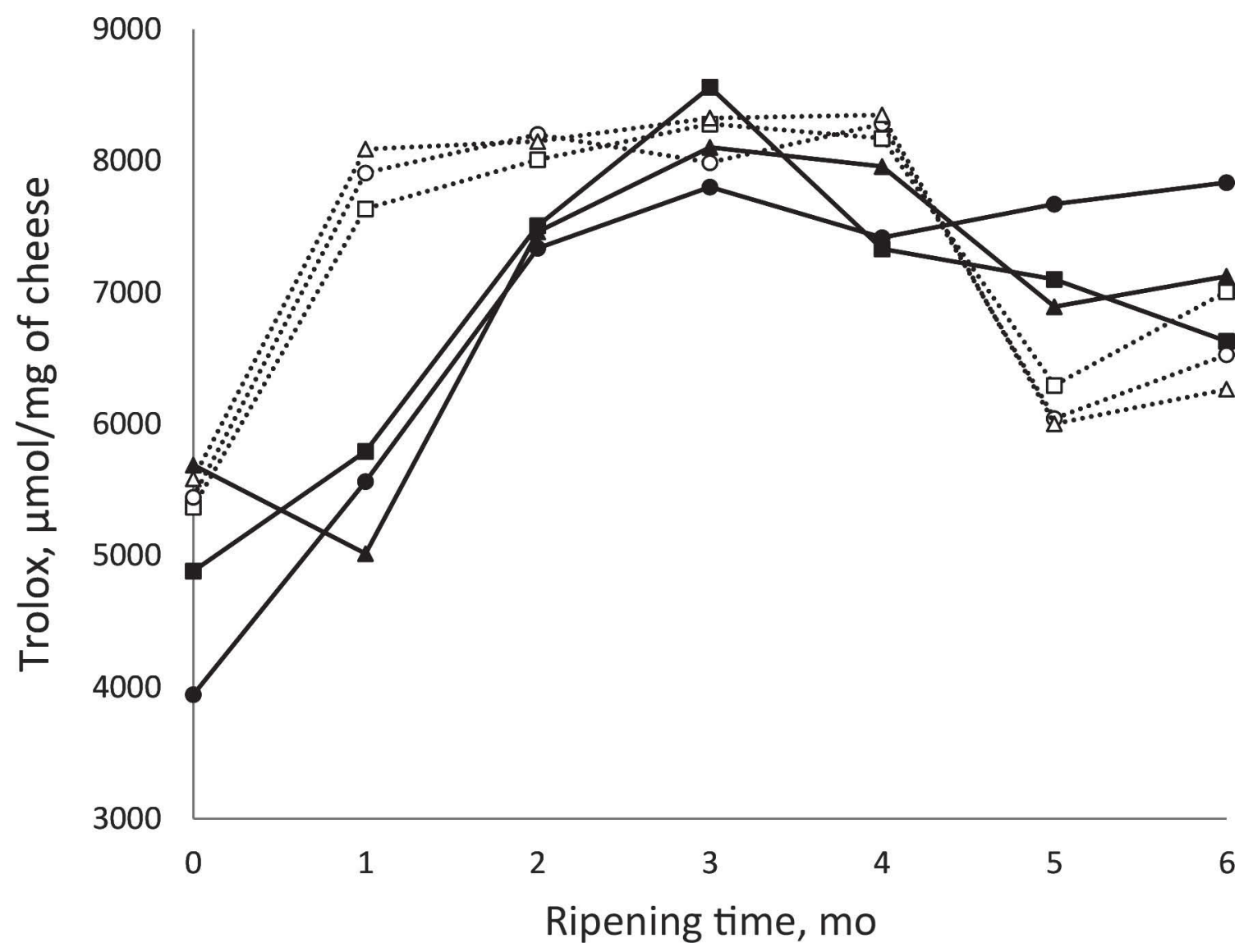

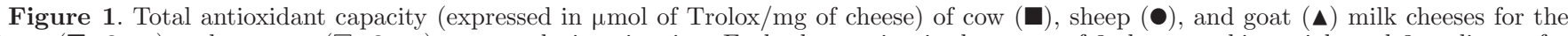
winter $(\mathbf{\square}, \boldsymbol{\bullet}, \mathbf{\Delta})$ and summer $(\square, \bigcirc, \Delta)$ seasons during ripening. Each observation is the mean of 3 cheese-making trials and 3 replicates for each trial. 
the increase was very pronounced from mo 0 to 1 , but more gradual up to mo 4 , followed by a sharp decline until mo 5. In contrast, in cheeses from winter milk, a constant increase was observed between mo 1 and 3 , followed by a stabilization or a progressive decrease in the case of cow milk cheeses.

This evolution is in agreement with reports in the literature and can be attributed to the progressive proteolysis of the proteins that produce soluble peptides and AA, such as sulfur-containing AA, with antioxidant ability (Gupta et al., 2009; Rashidinejad et al., 2013; Perna et al., 2015). Previous work on similar cheeses (González-Martín et al., 2009) revealed that the total water-soluble peptide content increased throughout ripening, being more extensive in the first month of ripening. This is in agreement with the strong increase in TEAC observed in the current study because, according to Gupta et al. (2009), antioxidant activity is higher in cheeses with a higher degree of early proteolysis. The decrease in TEAC after the fifth month of ripening indicates that the antioxidant peptides were not resistant to further proteolysis (Gupta et al., 2009).

We also detected a significant correlation between antioxidant capacity and seasonality $(\mathrm{r}=-0.239, P<$ 0.01 ). Antioxidant capacity values were higher in summer than in winter due to the higher TEAC values observed at 0 mo (except for goat winter cheese) and mainly at 1 and 2 mo in the summer cheeses (Figure 1).

Examining the influence of seasonality on the ripening process showed that summer cheeses had lower hydrophobic:hydrophilic ratios than winter cheeses, especially after the first month of ripening, indicating strong proteolysis (results published in Vivar-Quintana et al., 2009). This is in agreement with reports of other authors and may be due, in part, to aminopeptidase activity of the lactic acid bacteria present in raw milk (Pérez-Elortondo et al., 1998; Mendia et al., 2000). However, it may also be due to the different composition of the milk samples, because the composition of the milk was not standardized before cheese-making (Chávarri et al., 1999). Thus, the lower initial antioxidant activity of the winter cheeses made from cow and ewe milk can be correlated with the conditions of milk production. In this sense, previous results concerning the effects of season showed that the lowest antioxidant capacity [assayed by both the ABTS and ferric reducing antioxidant power (FRAP) methods] was found in the winter months for ewe milk (Revilla et al., 2012). In some cheeses, antioxidant activity has been correlated with contents of vitamin $\mathrm{E}$ and $\beta$-carotene (Lucas et al., 2006 a,b). In agreement with this, the summer cheeses in our trials were characterized by a higher content of vitamin A (Revilla et al., 2014). Moreover, previous works in similarly manufactured cheeses reported that summer cheeses had higher total contents of watersoluble peptides (Vivar-Quintana et al., 2009) and a lower fat content (González-Martín et al., 2011b). Although a positive correlation was observed between fat content and TEAC (Figure 2) in our study, the fatty acid profile was affected by season-summer cheeses had a higher content of PUFA (2.85 vs. $2.33 \mathrm{~g} / 100 \mathrm{~g}$ of fatty acids), which is, according to Lucas et al. (2008a), positively correlated with antioxidant activity.

Finally, no significant effect of species was observed $(\operatorname{cow}=7,046 \pm 1,252$; ewe $=6,977 \pm 1,419$; goat $=$ $7,078 \pm 1,273 \mu \mathrm{mol}$ of Trolox $/ \mathrm{mg}$ of cheese), in agreement with the findings of Lucas et al. (2006b), who used the FRAP assay method. The absence of differences in TEAC due to species is correlated with the absence of differences in the contents of vitamins A and E (Revilla et al., 2014) and in the values of soluble peptides (Vivar-Quintana et al., 2009).

\section{Correlation Studies}

From the above, it may be deduced that antioxidant capacity is affected by many factors. The results concerning the components seen to exert a significant influence are shown in Figure 2. Figure 2 reveals the existence of a positive correlation between antioxidant capacity and the percentage of fat $(\mathrm{r}=0.308)$, as observed previously by Lucas et al. (2008a) using the FRAP assay in cow and goat cheese. This can be attributed more to the correlation of fatty acids with other antioxidants than to the antioxidant activity of the fat. The positive correlation between the percentage of protein and TEAC $(\mathrm{r}=0.366)$ occurs because the latter parameter is primarily associated with caseins (de Renobales et al., 2012), the major radical-scavenging proteins in milk (Cervato et al., 1999; Clausen et al., 2010).

Positive significant correlations $(P<0.000)$ between TEAC and $\mathrm{K}(\mathrm{r}=0.385), \mathrm{Mg}(\mathrm{r}=0.312), \mathrm{Na}(\mathrm{r}=$ $0.432)$, and $\mathrm{P}(0.272)$ were observed. The positive correlations between minerals and TEAC are generally in agreement with the results obtained by Lucas et al., (2008a), except for $\mathrm{K}$ that, in the previous work, showed a negative correlation with TEAC.

The observed positive correlations between the mineral contents and TEAC are probably due to the significant positive correlation between protein content (because TEAC is primarily associated with caseins) and these minerals $(P<0.0001)$, the correlation coefficients between protein and the different minerals being as follows: $\mathrm{K}(\mathrm{r}=0.721), \mathrm{Mg}(\mathrm{r}=0.305), \mathrm{Na}(\mathrm{r}=$ $0.666)$, and $\mathrm{P}(\mathrm{r}=0.594)$. Statistical analysis showed 

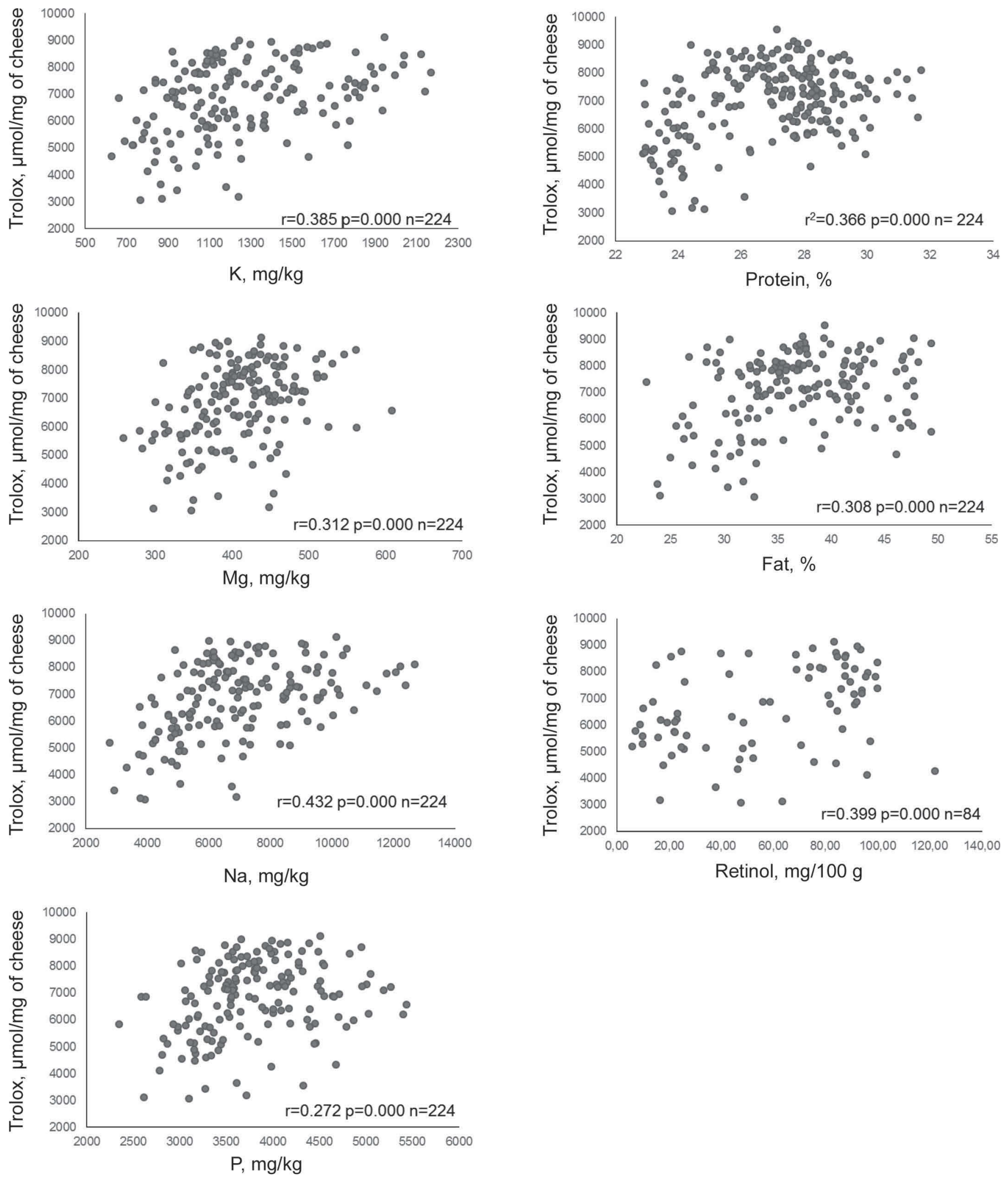

Figure 2. Correlation between Trolox equivalent antioxidant capacity (TEAC, $\mu$ mol of Trolox/mg of cheese) and other chemical components in cheeses of different compositions and ripening time. 
Table 3. Statistical descriptors ${ }^{1}$ of the near infrared calibration for the determination of antioxidant capacity in cheese

\begin{tabular}{|c|c|c|c|c|c|c|}
\hline Item & $\mathrm{N}$ & $\mathrm{SD}$ & Estimate & $\mathrm{R}^{2}$ & SECV & $\mathrm{RPD}$ \\
\hline
\end{tabular}

${ }^{1} \mathrm{~N}=$ number of samples; SECV $=$ standard error of cross-validation; RPD = residual predictive deviation.

that $\mathrm{Zn}$ and $\mathrm{Ca}$ were not significantly correlated with TEAC or with protein content.

A positive correlation was observed between TEAC and retinol $(\mathrm{r}=0.399)$. Significant correlations have been found between antioxidant capacity and $\beta$-carotene in cow and goat cheese, because $\beta$-carotene is an antioxidant compound that is only slightly influenced by the cheese-making process, but no significant correlations were found between antioxidant capacity and retinol (Lucas et al., 2006a,b, 2008a). However, in ewe milk, $\beta$-carotene is fully converted into retinol, as mentioned previously. Finally, unlike previous reports (Lucas et al., 2006b, 2008a), no significant correlation was found between TEAC and $\alpha$-tocopherol; the cheeses analyzed in the current trial did not show differences in $\alpha$-tocopherol due to animal species, season, or ripening stage (Revilla et al., 2014).

\section{NIR Calibration Equation}

The NIR spectra were acquired using a remote reflectance fiber-optic probe that was applied directly to the cheese samples. The cheese samples were divided into 2 sets: the calibration set, with 160 samples, and the external validation set, with 64 samples. All samples were selected randomly so that all the variability of the group of cheeses would be represented. After the PCA analysis, the spectral variance explained was $>99 \%$, with 14 principal components. As previously described, samples with an $\mathrm{H}$ value $>3.0$ are considered different from the spectral population; therefore, in this case, 2 samples were removed from the set. Moreover, 4 samples were removed from the set based on the $\mathrm{T}$ criterion.

Calculation of the statistical parameters of the calibration equation for antioxidant capacity in cheeses is shown in Table 3. The table indicates the number of samples used to obtain the calibration equation after the removal of some samples for spectral ( $\mathrm{H}$ criterion) or chemical ( $\mathrm{T}$ criterion) reasons, together with the concentration range for antioxidant capacity and standard deviation. The equation developed for the determination of antioxidant capacity measured in cheeses of variable composition had an $\mathrm{R}^{2}$ value of 0.63 , with a SECV lower than the standard deviation. The range of TEAC values (determined by NIRS) that can be applied to cheese samples $(3,005.7-11,053.5 \mu \mathrm{mol}$ of Trolox/mg of cheese) is higher than the chemical reference data.

\section{Internal Validation}

The calibration model was assessed by cross-validation. The results, based on the correlation of the values obtained at the laboratory compared with those predicted by NIR for the antioxidant capacity, had an $\mathrm{R}^{2}$ of 0.65 , and very similar SEP and $\operatorname{SEP}(\mathrm{C})$ (standard error of prediction corrected with biases) values (796 and 798 , respectively), corresponding to $8.3 \%$ of the mean value of the antioxidant capacity. This indicates that the whole set of cheese samples in the calibration model behaved in the same way and that the model obtained by NIR can be applied to unknown samples. The prediction capacity was evaluated by RPD value; For the NIRS model, this value was 1.43.

\section{External Validation}

The calibration equation was used to predict antioxidant capacity in unknown samples of variable composition; that is, samples that were not used in the calibration model. The accuracy of the developed model was confirmed by applying it to 64 samples for external validation. To accomplish this, only the recordings of the NIR spectra of the samples belonging to the external validation set were used, and the values predicted by NIR spectroscopy were compared with the reference data measured previously. The NIRS and chemical methodologies were compared using Student's $t$-test for paired values. The level of significance obtained was 0.48 , which indicated an absence of statistical differences between methods. The predicted values of antioxidant capacity using NIRS technology were comparable to those obtained using chemical methods. This result shows that NIR technology has an interesting potential for determining cheese antioxidant activity because ABTS is a very time-consuming method and, like most methods for the determination of antioxidant capacity, it has its own drawbacks, among them the fact that ABTS is not found in the biology of mammals and hence represents a "nonphysiological" source of radicals. Moreover, in slow reactions, TEAC does not reach 
the end point and the reaction might be considered to have finished when, in fact, this is not the case (Van den Berg et al., 1999).

\section{CONCLUSIONS}

This work revealed a strong influence of time of ripening and season on cheese antioxidant activity that can be attributed mainly to progressive proteolysis during ripening and to conditions of milk production that resulted in higher antioxidant activity in summer cheeses. The total antioxidant capacity of cheeses was positively correlated with the content of some antioxidant compounds, such as total protein content and retinol, but also with total fat content and minerals because of their correlation with other antioxidant compounds. The NIRS technique shows good potential as a method to analyze antioxidant capacity; moreover, the method requires no sample preparation, it is cost effective, and has a short analysis time. Use of NIR has some limitations, partly because the chemical method is debatable (i.e., the reaction does not reach the end point, the ABTS is a nonphysiological source of radicals, and so on). It is a promising option, although its study should be broadened to samples from different geographic areas to obtain a model with greater applicability.

\section{ACKNOWLEDGMENTS}

The authors are grateful to Spanish Junta de Castilla y León (SA13908; Valladolid, Spain) for financial support.

\section{REFERENCES}

AOAC International. 1995. Official Methods of Analysis. 16th ed. AOAC International, Gaithersburg, MD.

Bounous, G. 2000. Whey protein concentrates (WPC) and glutathione modulation in cancer treatment. Anticancer Res. 20:4785-4792.

Cervato, G., R. Cazzola, and B. Cestaro. 1999. Studies on the antioxidant activity of milk casein. Int. J. Food Sci. Nutr. 50:291-296.

Chávarri, F., M. A. Bustamante, A. Santisteban, M. Virto, L. J. R. Barrón, and M. de Renobales. 1999. Changes in free fatty acids during ripening of Idiazabal cheese manufactured at different times of the year. J. Dairy Sci. 82:885-890.

Chen, J., H. Lindmark-Månsson, L. Gorton, and B. Åkesson. 2003. Antioxidant capacity of bovine milk as assayed by spectrophotometric and amperometric methods. Int. Dairy J. 13:927-935.

Clausen, M. R., C. Connolly, L. H. Skibsted, and J. Stagsted. 2010. Oxidative stability of bovine milk determined by individual variability in herd irrespective of selenium status. Int. Dairy J. 20:507513.

Colbert, L. B., and E. A. Decker. 1991. Antioxidant activity of an ultrafiltration permeate from acid whey. J. Food Sci. 56:1248-1250.

D'Urso, S., M. I. Cutrignelli, S. Calabro, F. Bovera, R. Tudisco, V. Piccolo, and F. Infascelli. 2008. Influence of pasture on fatty acid profile of goat milk. J. Anim. Physiol. Anim. Nutr. (Berl.) 92:405410 .
Davies, A. M. C., and P. Williams. 1996. Near Infrared Spectroscopy: The Future Waves. Proc. 7nth Int. Conf. Near Infrared Spectroscopy. NIR Publications, Chichester, UK.

De Feo, V., E. Quaranta, V. Fedele, S. Claps, R. Rubino, and C. Pizza. 2006. Flavonoids and terpenoids in goat milk in relation to forage intake. Ital. J. Food Sci. 18:85-92.

de Renobales, M., G. Amores, J. Arranz, M. Virto, L. J. R. Barrón, M. A. Bustamante, J. C. Ruiz de Gordoa, A. I. Nájera, I. Valdivielso, E. Abilleira, I. Beltrán de Heredia, F. J. Pérez-Elortondo, R. Ruiz, M. Albisu, and N. Mandaluniz. 2012. Part-time grazing improves sheep milk production and its nutritional characteristics. Food Chem. 130:90-96.

Dhanoa, M. S., S. J. Lister, and R. J. Barnes. 1995. On the scales associated with near-infrared reflectance difference spectra. Appl. Spectrosc. 49:765-772.

Dimick, P. S., and A. Kilara. 1983. Photooxidative changes in milk proteins and amino acids. Kieler Milch. Forschung 35:289-299.

Focant, M., E. Mignolet, M. Marique, F. Clabots, T. Breyne, D. Dalemans, and Y. Larondelle. 1998. The effect of vitamin E supplementation of cow diets containing rapeseed and linseed on the prevention of milk fat oxidation. J. Dairy Sci. 81:1095-1101.

González-Martín, I., J. M. Hernández-Hierro, I. Revilla, A. M. VivarQuintana, and I. Lobos-Ortega. 2011a. The mineral composition ( $\mathrm{Ca}, \mathrm{P}, \mathrm{Mg}, \mathrm{K}, \mathrm{Na}$ ) in cheeses (cow's, ewe's and goat's) with different ripening times using near infrared spectroscopy with a fibreoptic probe. Food Chem. 127:147-152.

González-Martín, I., J. M. Hernández-Hierro, J. Salvador-Esteban, C. González-Pérez, I. Revilla, and A. M. Vivar-Quintana. 2011b. Discrimination of seasonality in cheeses by near-infrared technology. J. Sci. Food Agric. 91:1064-1069.

González-Martín, I., J. M. Hernández-Hierro, A. M. Vivar-Quintana, I. Revilla, and C. González-Pérez. 2009. The application of near infrared spectroscopy technology and a remote reflectance fibreoptic probe for the determination of peptides in cheeses (cow's, ewe's and goat's) with different ripening times. Food Chem. 114:1564-1569.

Gupta, A., B. Mann, R. Kumar, and R. B. Sangwan. 2009. Antioxidant activity of Cheddar cheeses at different stages of ripening. Int. J. Dairy Technol. 62:339-347.

ISO. 1975. Cheese. Determination of fat content. Van Gulik method (ISO 3433). International Organization for Standardization, Geneva, Switzerland.

Lindmark-Månsson, H., and B. Åkesson. 2000. Antioxidative factors in milk. Br. J. Nutr. 84:S103-S110.

Lindmark-Månsson, H., J. Chen, M. Paulsson, G. Alden, B. Ren, R. Ladenstein, and B. Åkesson. 2001. The effect of storage and heat treatment on glutathione peroxidase in bovine milk and whey. Int. Dairy J. 11:71-81.

Lucas, A., C. Agabriel, B. Martin, A. Ferlay, I. Verdier-Metz, J. B. Coulon, and E. Rock. 2006a. Relationships between the conditions of cow's milk production and the contents in components of nutritional interest in raw milk farmhouse cheese. Lait 86:177-202.

Lucas, A., D. Andueza, E. Rock, and B. Martin. 2008a. Prediction of dry matter, fat, $\mathrm{pH}$, vitamins, minerals, carotenoids, total antioxidant capacity and color in fresh and freeze-dried cheeses by Visible-Near-Infrared reflectance spectroscopy. J. Agric. Food Chem. 56:6801-6808.

Lucas, A., J. B. Coulon, C. Agabriel, Y. Chilliard, and E. Rock. 2008b. Relationships between the conditions of goat's milk production and the contents of some components of nutritional interest in Rocamadour cheese. Small Rumin. Res. 74:91-106.

Lucas, A., E. Rock, J. F. Chamba, I. Verdiez-Metz, P. Brachet, and J. B. Coulon. 2006b. Respective effects of milk composition and the cheese compositional variability in components of nutritional interest. Lait 86:21-41.

Meglia, G. E., S. K. Jensen, C. Lauridsen, and K. P. Waller. 2006. Tocopherol concentration and steroisomer composition in plasma and milk from dairy cows fed natural and synthetic vitamin $\mathrm{E}$ around calving. J. Dairy Res. 73:227-234.

Mel'uchova, B., J. Blasko, R. Kubinec, R. Gorova, J. Dubravska, M. Margetin, and L. Sojak. 2008. Seasonal variations in fatty acid 
composition of pasture forage plants and CLA content in ewe milk fat. Small Rumin. Res. 78:56-65.

Mendia, C., F. C. Ibañez, P. Torre, and Y. Barcina. 2000. Influence of the season on proteolysis and sensory characteristics of Idiazabal cheese. J. Dairy Sci. 83:1899-1904.

O'Connell, J. E., and P. F. Fox. 2001. Significance and applications of phenolic compounds in the production and quality of milk and dairy products: A review. Int. Dairy J. 11:103-120.

Pérez-Elortondo, F. J., P. Aldámiz-Echebarria, M. Albisu, and Y. Barcina. 1998. Indigenous lactic acid bacteria in Idiazabal ewes' milk cheese. Int. Dairy J. 8:725-732.

Perna, A., I. Intaglietta, A. Simonetti, and E. Gambacorta. 2015. Effect of genetic type on antioxidant activity of Caciocavallo cheese during ripening. J. Dairy Sci. 98:3690-3694.

Rashidinejad, A., E. J. Birch, D. Sun-Waterhouse, and D. W. Everett. 2013. Effects of catechin on the phenolic content and antioxidant properties of low-fat cheeses. Int. J. Food Sci. Technol. 48:2448-2455

Re, R., N. Pellegrini, A. Proteggente, A. Pannala, M. Yang, and C. A. Rice-Evans. 1999. Antioxidant activity applying an improved ABTS radical cation decolorization assay. Free Radic. Biol. Med. 26:1231-1237.

Revilla, I., I. Lobos-Ortega, A. M. Vivar-Quintana, M. I. GonzálezMartín, J. M. Hernández-Hierro, and C. González-Pérez. 2014. Variations in the contents of vitamins $\mathrm{A}$ and $\mathrm{E}$ during the ripening of cheeses with different compositions. Czech J. Food Sci $32: 342-347$.
Revilla, I., C. Palacios, C. Hidalgo, R. Alvarez, and P. Rodríguez. 2012. Effect of production system, organic vs conventional on antioxidant capacity of sheep milk. Landbauforschung 362:233-236.

Rubino, R., S. Claps, and V. Fedele. 2000. Herbe paturê et qualite'organoleptique et nutritionnelle du lait et du fromage de chèvre (Nature of grazed grass and organoleptic and nutritional quality of goat milk and cheese). Pages 48-54 in Proc. Seminar Luz St Sauveur, FAO REU Serie Technology, Rome, Italy.

Shenk, J. S., and M. O. Westerhaus. 1995. Analysis of Agriculture and Food Products by Near Infrared Reflectance Spectroscopy, Monograph, NIRSystems, Silver Spring, MD.

Shingfield, K. J., M. Bonnet, and N. D. Scollan. 2013. Recent developments in altering the fatty acid composition of ruminant-derived foods. Animal 7:132-162.

Steijns, J. M., and A. C. van Hooijdonk. 2000. Occurrence, structure, biochemical properties and technological characteristics of lactoferrin. Br. J. Nutr. 84:S11-S17.

Van den Berg, R., G. R. M. M. Haenen, H. Van den Berg, and A. Bast. 1999. Applicability of an improved Trolox equivalent antioxidant capacity (TEAC) assay for evaluation of antioxidant capacity measurements of mixtures. Food Chem. 66:511-517.

Vivar-Quintana, A. M., M. A. Blanco-López, I. Revilla, I. GonzálezMartín, J. M. Hernández-Hierro, and C. González-Pérez. 2009. Seasonal evolution of hydrophilic and hydrophobic peptide contents in cheeses made from ewe's goat's or cow's milk. Czech J. Food Sci. 27:106-108. 